\title{
Hypotensive Action and Side Effects of Clonidine-Chlorthalidone and Methyldopa-Chlorthalidone in Treatment of Hypertension
}

\author{
A. AMERY,* M.D. ; M. VERSTRAETE, $†$ M.D. ; H. BOSSAERT, $₫ \$ M.D. ; G. VERSTREKEN, $\ddagger$ M.D.
}

\begin{abstract}
Cummary: In an open, randomized, cross-over study $\checkmark$ the hypotensive action and side effects of clonidine-chlorthalidone and methyldopa-chlorthalidone combinations were compared. The diastolic morning blood pressure could be reduced to $95 \mathrm{~mm}$. $\mathrm{Hg}$ or below in significantly more patients with clonidine than with methyldopa. Side effects, however, were more commonly encountered during the clonidine than during the methyldopa phase.
\end{abstract}

\section{Introduction}

It has been shown conclusively that clonidine produces a substantial lowering of blood pressure during prolonged oral treatment of hypertensive patients. The exact place of this new drug among hypotensive agents is as yet unspecified. It seemed to us that a comparative study of clonidine and one or more established hypotensive agents would be useful, with special attention to their respective hypotensive actions and the nature and frequency of side effects during prolonged oral administration in ambulant patients. This paper reports an open, randomized, cross-over study comparing clonidine and methyldopa.

Chlorthalidone was associated with both drugs since a diuretic enhances the hypotensive effect of methyldopa (Wilson et al., 1963; Colwil et al., 1964; Smith et al., 1966) and clonidine (Jungling, 1968; Onesti et al., 1969).

\section{Patients and Methods}

\section{Selection of Patients}

Before admission to the study patients had to fulfil all of the following positive and none of the negative criteria.

Positive Criteria.-A persistently raised diastolic blood pressure (measured in the hospital, in the outpatient clinic, or by the house physician) of $110 \mathrm{~mm}$. Hg or more. A persistent diastolic blood pressure of $90 \mathrm{~mm}$. $\mathrm{Hg}$ or more during diuretic treatment $(50 \mathrm{mg}$. of chlorthalidone daily). The patient had to be willing to collaborate and able to record his own blood pressure at home four times each day: recumbent before rising in the morning, standing within five minutes after rising in the morning, standing in the evening before going to bed, and recumbent in the evening after five minutes' rest in bed.

Negative Criteria.-Presence of grade IV retinopathy (Keith Wagener) at any time before admission to the study. Severe renal insufficiency: two subsequent determinations of a serum creatinine of $4 \mathrm{mg}$. $/ 100 \mathrm{ml}$. or more. Hypertension secondary to Conn's or Cushing's syndrome or to a phaeochromocytoma. No contraindications to thiazide treatment-that is, serum uric acid level of $10 \mathrm{mg} . / 100 \mathrm{ml}$. or more, with or without diuretic; symptoms of gout before or during diuretic treatment; severe diabetes mellitus requiring 40 units of insulin or more; and digitalis administration.

\section{Preliminary Investigation}

All patients underwent investigation, including a history; physical examination including fundoscopy; chest $x$-ray exam-

\footnotetext{
* Teacher of Medicine, Section of Cardiology; Head of the Hypertension Laboratory.

+ Professor of Medicine; Head of the Section of Blood Coagulation.

Assistant, Department of Medicine.

Investigator of the Belgium Research Council.

University of Louvain, Belgium.
}

ination; electrocardiogram; creatinine, electrolytes, and uric acid in serum; blood glucose; 24-hour creatinine clearance; intravenous pyelogram; and urine examination for glucose and protein and microscopy of the sediment. Other tests, including urinary catecholamines, arteriography of the renal arteries, etc., were performed when indicated.

\section{Therapeutic Regimen}

Throughout the study all patients received $50 \mathrm{mg}$. of chlorthalidone daily. All other antihypertensive agents were interrupted at least one month before admission to the study. The decision to admit a patient to the study was made after repeated visits to the hypertension clinic when the results of the tests mentioned above were available and when it was certified that the patient was able to take correctly his blood pressure at home.

Patients admitted on an even day began with methyldopa (250 mg. per tablet). It was planned to adjust the number of tablets weekly until the recumbent morning diastolic blood pressure, recorded by the patient, was $90 \mathrm{~mm}$. $\mathrm{Hg}$ or less, or until a maximum of 10 tablets a day was reached. Patients were seen at monthly intervals at the hypertension clinic, where the number of tablets was altered if required. The patient was transferred to clonidine $(0.3 \mathrm{mg}$. per tablet) treatment if sufficient blood-pressure control was obtained during the previous month or when, notwithstanding the daily intake of $10 \times 250$-mg. tablets of methyldopa, the blood pressure was not sufficiently controlled. The same decision was taken if the blood pressure remained too high and further increase of drug intake seemed to be impossible because of side effects. During the clonidine phase the daily intake was also increased to a maximum of 10 tablets a day. Patients admitted on an uneven day started with clonidine and were transferred to methyldopa, the same criteria being used.

The shortest time the patients were on one drug was two months; most of them took each drug during three months, and the longest phase on one drug was four months. The tablets were taken three times a day-on rising in the morning after blood-pressure measurement, at noon, and before sleeping at night after blood-pressure measurement. If fewer than three tablets were taken the noon and morning doses were omitted; if three or more tablets were taken they were divided into three doses, the evening dose being equal to or greater than the others.

\section{Controls}

The patients measured their blood pressure at home four times a day and noted the results on a special data sheet, which was handed to the doctor at each outpatient visit. The mean and standard deviations of the last 10 days were calculated and used in the figures given in the Tables.

During each visit to the hypertension clinic three points were checked. (1) The patients were questioned on the nature and number of tablets, and by use of a questionnaire the frequency and importance of side effects were recorded (see Table VIII). (2) Blood-pressure readings taken in recumbent and standing positions by the patient with his own egotest

II Supplied by Bayer as Presinol.

I Kindly supplied by Boehringer Ingelheim; the commercially available Catapres tablets contain only $0.15 \mathrm{mg}$. of clonidine. 
apparatus were compared with data obtained by the doctor using a mercury-calibrated blood-pressure apparatus. The patients were instructed to use phase 5 of the Korotkoff sounds as the diastolic pressure. (3) Electrolytes, creatinine, and uric acid in the serum were determined.

\section{Results \\ Patients Admitted to the Study}

Data showing the aetiology and severity of the hypertension in the 41 patients are given in Table I. Drugs other than chlorthalidone, clonidine, or methyldopa were interrupted except in one patient who was maintained on insulin (24

TABLE I.-Characteristics of the Group of 41 Patients Studied Age (Years) Mean \pm S.D. Sex f Female $47 \cdot 5+11 \cdot 3$ Male 19

Retinopathy Grade<smiles>[Al]C#[Al]</smiles>
5
26
10
0 Electrocardiogram Normal Left ventricular hypertrophy $\left\{\begin{array}{l}\text { Infarction } \\ \text { Auricular fibrillation }\end{array}\right.$

Aetiology of hypertension Essential Glomerulonephritis Pyelonephritis
Polycystic kidneys

Creatinine clearance $(\mathrm{ml}$.)

Blood pressure without treatment $\quad\{$ Systolic $(\mathrm{mm} . \mathrm{Hg})$ $206 \cdot 8 \pm 26 \cdot 4$

units daily). The 24-hour proteinuria was less than $0.5 \mathrm{~g}$. in 40 patients; the patient with chronic glomerulonephritis excreted $3.5 \mathrm{~g}$. of protein a day. No patient had congestive heart failure on admission and none was taking digitalis.

\section{Dose of Drugs Eventually Taken}

The dose of the drugs taken by the patients averaged 1.23 mg. of clonidine a day and $1.75 \mathrm{~g}$. of methyldopa a day. Therefore in this group $1.75 \mathrm{~g}$. of methyldopa ( 7 tablets of $250 \mathrm{mg}$.) corresponded to $1.23 \mathrm{mg}$. of clonidine $(4.1$ tablets of $0.3 \mathrm{mg}$.) or $0.7 \mathrm{mg}$. of clonidine corresponded to $1 \mathrm{~g}$. of methyldopa. The equivalence in individual cases varied from 0.12 to $1.5 \mathrm{mg}$. of clonidine per $\mathrm{g}$. of methyldopa.

There were three reasons for not further increasing the drug dosage above the amounts mentioned: sufficient bloodpressure control (diastolic recumbent morning pressure $<95 \mathrm{~mm}$. $\mathbf{~ H g}$ ) in 25 patients on methyldopa and 34 on clonidine, side effects in 5 patients on methyldopa and 3 on clonidine, and in 11 patients on methyldopa and 4 on clonidine because the required dose would have exceeded the set maximal dosage of 10 tablets a day.

TABle II.-Blood Pressure at End of Each Phase

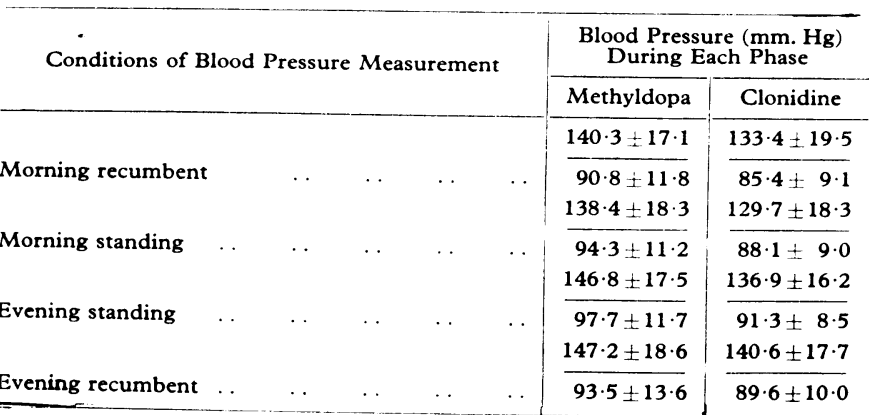

\section{Blood-pressure Response}

Blood pressure at End of Each Phase.-The mean and standard deviation calculated from the average blood pressures obtained for each patient in different conditions during the last 10 days of each phase are given in Table II.

Diastolic Pressure taken at Home in the Morning.-The number of patients whose blood pressure was $95 \mathrm{~mm}$. $\mathrm{Hg}$ or lower when measured at home in the morning in the recumbent position was significantly $(0.05>P>0.02)$ higher at the end of the clonidine phase than at the end of the methyldopa administration (Table III). The same trend was also noted when the pressure was measured at other times of the day, in the standing position, or when the systolic values were taken into account. One possible explanation for this difference could be that several patients had been treated with methyldopa before entering the study and had developed some resistance to the drug. Therefore analogous calculations made with the $\chi^{2}$ two-tailed test were repeated on the restricted group of patients who did not receive either methyldopa or clonidine before admission to the study; a significant $(0.02>$ $\mathbf{P}>0.01$ ) difference was still observed (Table IV).

Difference Between Morning and Evening Blood pressures.A lower blood pressure in the morning has often been observed in hypertensive patients both when untreated and when receiving therapy, especially with guanethidine. The differences in recumbent morning and evening systolic and diastolic readings during methyldopa and clonidine treatment are shown in Table V. During both the methyldopa and the clonidine therapy the pressure tends to be higher in the evening. This difference reaches a level of significance during clonidine therapy for the systolic (0.05> P $>0.001)$ and diastolic pressure $(\mathrm{P}<0.001)$ and also during methyldopa therapy for the systolic $(\mathrm{P}<0.001)$ and diastolic $(0.05>$ $P>0.001)$ pressure. The rise in the recumbent systolic pressure from morning to evening tended to be more pronounced during methyldopa $(7.25 / 3.04 \mathrm{~mm}$. $\mathrm{Hg}$ ) therapy than during clonidine treatment $(6.99 / 4.42 \mathrm{~mm} . \mathrm{Hg})$; this was, however, not significant $(P>0 \cdot 1)$. The same tendency can be seen for

TABLE III.-Response of the Recumbent Morning Home Diastolic Blood Pressure to Both Drugs

\begin{tabular}{rlll|c|c}
\multicolumn{3}{c}{ Blood Pressure (mm. Hg) } & & \multicolumn{2}{c}{$\begin{array}{c}\text { No. of Patients at End of } \\
\text { Each Phase }\end{array}$} \\
\cline { 3 - 6 } & & & & Methyldopa & Clonidine \\
\hline 995 & $\ldots$ & $\ldots$ & $\cdots$ & 16 & 7 \\
\hline Total & $\ldots$ & $\ldots$ & $\cdots$ & 41 & 34 \\
\hline
\end{tabular}

$0.05>\mathrm{P}>0.02$.

TABLE IV.-Response of Recumbent Morning Blood Pressure to Both Drugs in Patients Not Previously Treated With One of Them

\begin{tabular}{|c|c|c|c|c|c|}
\hline \multirow{2}{*}{\multicolumn{4}{|c|}{ Blood Pressure (mm. Hg) }} & \multicolumn{2}{|c|}{$\begin{array}{l}\text { No. of Patients at End of } \\
\text { Each Phase }\end{array}$} \\
\hline & & & & \multirow{2}{*}{$\begin{array}{c}\text { Methyldopa } \\
15 \\
19\end{array}$} & \multirow{2}{*}{$\begin{array}{c}\text { Clonidine } \\
5 \\
29\end{array}$} \\
\hline $\begin{array}{l}\geq 95 \\
\leqslant 95\end{array}$ & $\cdots$ & $\cdots$ & $\begin{array}{l}\ldots \\
\cdots\end{array}$ & & \\
\hline Total & $\ldots$ & $\ldots$ & $\ldots$ & 34 & 34 \\
\hline
\end{tabular}

$0.02>P>0.01$

TABLE V.-Differences Between Recumbent Evening Minus Recumbent Morning Blood Pressure

\begin{tabular}{|c|c|c|c|}
\hline & $\begin{array}{l}\text { Methyldopa } \\
\overline{\mathrm{X}} \pm \text { S.D. }\end{array}$ & $\begin{array}{l}\text { Clonidine } \\
\overline{\mathbf{X}}+\text { S.D. }\end{array}$ & $\begin{array}{c}\text { P between } \\
\text { Methyldopa } \\
\text { and } \\
\text { Clonidine }\end{array}$ \\
\hline $\begin{array}{l}\text { Differences in Systolic B.P. } \\
\quad(\mathrm{mm} \text {. Hg) } \\
\mathbf{P} \text { Value of these differences }\end{array}$ & $\begin{array}{c}7.25 \pm 8.93 \\
<0.001\end{array}$ & $\begin{array}{c}6.99 \pm 13 \\
0.05>P>0.001\end{array}$ & $>0.1$ \\
\hline $\begin{array}{l}\text { Differences in Diastolic B.P. } \\
\text { (mm. Hg) } \\
P \text { Value of these differences }\end{array}$ & $\begin{array}{c}3.04 \pm 6.06 \\
0.05>P>0.001\end{array}$ & $\begin{array}{l}4 \cdot 42 \pm 7.03 \\
<0 \cdot 001\end{array}$ & $>0.1$ \\
\hline
\end{tabular}


the diastolic pressure. The differences between standing morning and standing evening systolic and diastolic pressure during methyldopa and clonidine treatment are shown in Table VI. The interpretation of the recumbent blood pressure also seems to be valid here.

Difference between Standing and Recumbent Blood Pressure.-Differences in recumbent and standing blood pressure during anti-hypertensive therapy, especially with blockers of the adrenergic neuromuscular transmission, can be a troublesome side effect and are most pronounced in the morning. These differences during clonidine and methyldopa administration of the lying and standing blood pressure are given in Table VII; they were significant only for the diastolic blood pressure. Though the fall on rising tends to be smaller during the clonidine than during the methyldopa treatment the difference was not significant $(P>0.05)$.

\section{Side Effects}

At the end of the clonidine and methyldopa phase each of the 41 patients was asked a series of set questions (Table VIII). Dryness of the mouth, constipation, and drowsiness were significantly more frequent $(P<0.001)$ during clonidine treatment. There was a tendency to more frequent headaches in the methyldopa phase. If, however, one does not consider the total number of patients (41) but only those in whom the blood pressure was sufficiently controlled with both drugs (18) the frequency of headaches $(17 \%)$ was the same with both drugs.

In some cases because of side effects the drug dosage could not be increased enough to bring the blood pressure to nor-

Table VI.-Differences Between Standing Evening Minus Standing Morning Blood Pressure

\begin{tabular}{|c|c|c|c|}
\hline & $\begin{array}{l}\text { Methyldopa } \\
\overline{\mathrm{X}}: \text { S.D. }\end{array}$ & $\begin{array}{l}\text { Clonidine } \\
\overline{\mathrm{X}}: \text { S.D. }\end{array}$ & $\begin{array}{l}\text { P between } \\
\text { Methyldopa } \\
\text { and } \\
\text { Clonidine }\end{array}$ \\
\hline $\begin{array}{l}\text { Differences in systolic B.P. } \\
\text { (mm. Hg) } \\
P \text { Value for these differences }\end{array}$ & $\begin{array}{c}8.9911 .33 \\
<0.001\end{array}$ & $\begin{array}{c}6.93+12.09 \\
<0.001\end{array}$ & $>0.05$ \\
\hline $\begin{array}{l}\text { Differences in diastolic B.P. } \\
\text { (mm. Hg) } . . \\
P \text { Value for these differences }\end{array}$ & $\begin{array}{c}3 \cdot 12+4 \cdot 73 \\
0 \cdot 001\end{array}$ & 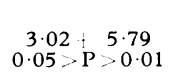 & $>0.05$ \\
\hline
\end{tabular}

Table VII.-Differences Between Recumbent Minus Standing Blood Pressure in the Morning

\begin{tabular}{|c|c|c|c|}
\hline & $\begin{array}{l}\text { Methyldopa } \\
\overline{\mathrm{X}}: \text { S.D. }\end{array}$ & $\begin{array}{l}\text { Clonidine } \\
\overline{\mathrm{X}} \text { S.D. }\end{array}$ & $\begin{array}{l}\text { P between } \\
\text { Methyldopa } \\
\text { and } \\
\text { Clonidine }\end{array}$ \\
\hline $\begin{array}{l}\text { Differences in systolic } \begin{array}{c}\text { B.P. } \\
\text { (mm. } \mathrm{Hg}) \\
\mathrm{P} \text { Value for these differences }\end{array} .\end{array}$ & $\begin{array}{c}1.51=4.99 \\
>0.05\end{array}$ & $\begin{array}{c}2.81 \\
>0.1\end{array}$ & $>0.05$ \\
\hline $\begin{array}{l}\text { Differences in diastolic B.P. } \\
\text { (mm. Hg) } \ldots \\
P \text { Value for these differences }\end{array}$ & $\begin{array}{c}+3.33 \quad 7.91 \\
0.02>P>0.01\end{array}$ & $\begin{array}{c}-2.94 \neq 6.72 \\
0.01>P>0.005\end{array}$ & 0.05 \\
\hline
\end{tabular}

TABle VIII.-Side Effects During Clonidine and Methyldopa Treatment of 41 Cases

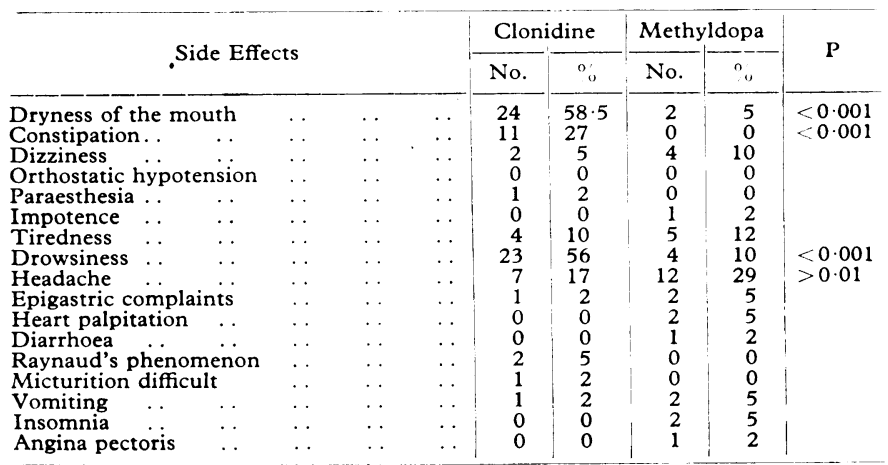

mal. This occurred in three patients during the clonidine phase and in five during methyldopa administration. Sedation in one patient and vomiting in another were severe enough to necessitate interruption of clonidine therapy. During administration of methyldopa side effects were never severe enough to make interruption of treatment necessary.

\section{Discussion}

\section{Present Data}

The study was neither a single nor a double-blind study; the tablets used were similar in taste, colour, and shape to the commercially available tablets of Presinol and Catapres respectively. In most instances these tablets were unknown to the patients before the start of the study; they were told that the drugs were different. Furthermore, no special procedures were used to ensure that the patients were in fact taking the tablets given to them on each visit to the hypertension clinic.

Our results showed that in a significantly greater number of patients the diastolic morning blood pressure could be reduced to $95 \mathrm{~mm} . \mathrm{Hg}$ or less with clonidine-chlorthalidone than with methyldopa-chlorthalidone. Since this difference was also seen in the patients not treated previously with one of these drugs, the possibility that some of the patients had developed resistance to one of the drugs before the study was excluded. On average each treatment phase (clonidine or methyldopa) was for about three months, as the number of pills was usually increased rather slowly and the patients were maintained on the individually maximum dose for one month. From the present data we do not know if the observed difference would also hold during longer periods of treatment. Side effects, however, were more commonly encountered during the chlorthalidone-clonidine phase than during the chlorthalidone-methyldopa phase, and more patients preferred the latter to the former combination of drugs.

When hypotensive treatment with clonidine or methyldopa is considered we would prefer, from these results, to start with the chlorthalidone-methyldopa combination, except when rapid blood-pressure control or some degree of sedation is desirable. If sufficient blood-pressure control cannot be achieved by the chlorthalidone-methyldopa treatment we would then use the other combination. The latter could be contraindicated when excessive sedation could become dangerous-for instance, in car drivers. On the other hand, if a patient is not controlled by a chlorthalidone-clonidine regimen it is unlikely that he will be controlled under a chlorthalidone-methyldopa regimen.

\section{Comparison with Published Data}

Jungling (1968), in the short-term treatment of four patients, administered $0.075 \mathrm{mg}$. of clonidine three times during six days and then $3.75 \mathrm{mg}$. of methyldopa three times during six days; the blood pressure at the end of each period was respectively $158 / 108$ and $158 / 100$. In four other patients the sequence was reversed and the blood pressure at the end of the methyldopa period was $183 / 99$ and at the end of the clonidine period $177 / 99 \mathrm{~mm}$. Hg. Side effects are not mentioned in this group.

So far as we know no controlled (open, single, or doubleblind) study comparing methyldopa and clonidine in the treatment of hypertension over a longer period of time has been published. Several groups have, however, transferred patients previously treated with methyldopa to clonidine treatment. In a preliminary report Seedat et al. (1969) described 30 patients treated in this way, stating that "effective" control of blood pressure was achieved with both drugs. Nevertheless, clonidine caused side effects in 23 and methyldopa in only 11 of the 30 patients. The nature of the side effects was similar to those described in our study. Smet et 
al. (1969) mentioned that a dose of 0.4 to $1.2 \mathrm{~g}$. of clonidine is equivalent to 1.5 to $2.0 \mathrm{~g}$. of methyldopa. These data and our present findings agree on the following points: that $0.7 \mathrm{mg}$. of clonidine corresponds to about $1 \mathrm{~g}$. of methyldopa, that blood-pressure control can be achieved at least as well with clonidine as with methyldopa, and that side effects are more frequent during clonidine than during methyldopa treatment.

The present study compares only clonidine-chlorthalidone to methyldopa-chlorthalidone. To specify the exact place of clonidine of prolonged treatment of hypertension a comparative study of clonidine and other antihypertensive agents is desirable.
REFERENCES

Colwil, J. M., Dutton, A. M., Morrissey, J., and Yu, R. N. (1964). New England fournal of Medicine, 271, 696.

Jungling, K. (1968). Medizinisches Welt, 39, 2105.

Onesti, G., Schwartz, A. B., Kim, K. E., Swartz, C., and Brest, A. N (1969). Circulation, 39, 219.

Seedat, Y. K., Vawda, E. I., Mitha, S., and Ramassar, R. (1969). Lancet, 2, 591 .

Smet, G., Hoobler, S. W., Sanbar, S., and Julius, S. (1969). American Heart Fournal, 77, 473.

Smith, W. M., Bachman, B., Galante, J. G., Hanowell, E. G., and Johnson, W. P. (1966). Annals of Internal Medicine, 65, 657.

Wilson, W. R., Okun, R., Tetreault, L., and Fallis, N. (1963). Journal o the American Medical Association, 185, 819.

\title{
Serum Fibrin/Fibrinogen Degradation Products Associated with Postoperative Pulmonary Embolus and Venous Thrombosis
}

\author{
C. V. RUCKLEY,* CH.M., F.R.C.S.ED. ; P. C. DAS, † M.B., B.S., PH.D. ; A. G. LEITCH, $\ddagger$ B.SC. \\ A. A. DONALDSON, $\$ M.R.C.P.ED., D.M.R.D. ; W. A. COPLAND, $\$ V.R.D., F.F.R., D.M.R.D. \\ A. T. REDPATH, $\|$ B.SC., PH.D., A.INST.P. ; P. SCOTTg; J. D. CASH, ${ }^{* *}$ PH.D., F.R.C.P.ED.
}

\begin{abstract}
Gummary: A total of 76 "high-risk" surgical patients $\checkmark$ were studied for evidence of venous thromboembolic disease. Episodes of deep vein thrombosis and of pulmonary embolism were related to changes in blood levels of fibrin degradation products (F.D.P.). When diagnosed either by ordinary clinical means or by venography and isotope scanning significantly raised F.D.P. levels were found in all cases. Serum F.D.P. estimations are unlikely to help in detecting deep vein thrombosis, but may prove valuable in diagnosing pulmonary embolism.
\end{abstract}

\section{Introduction}

Accurate diagnosis is essential to the evaluation of treatment. Nowhere is this better illustrated than in assessing a widening range of therapy for venous thromboembolic disease. It is now universally recognized that deep vein thrombosis is not reliably detected by clinical examination. Robertson (1968) concluded that the frequency with which venous thrombosis has been diagnosed before death varies between 5 and $26 \%$. This has been confirmed by studies where the diagnosis could be substantiated by necropsy (Gibbs, 1957; Sevitt and Gallagher, 1961; Freiman et al., 1965), isotope studies (Atkins and Hawkins, 1968; Negus et al., 1968), or the use of ultrasonics (Strandness et al., 1967; Sigel et al., 1968).

Pulmonary embolism too is seriously underdiagnosed, and possibly a positive diagnosis before death is made in only 30 to $50 \%$ of cases (Prettin, 1936; Smith et al., 1965). Moreover, patients in whom minor or silent episodes, or both, are left untreated may die from further embolism or extension of thrombi from the original embolus-sequelae which may be prevented by adequate systemic treatment with heparin (Thomas, 1965). Morrell et al. (1963) calculated that between

\footnotetext{
- Senior Surgical Registrar, University Department of Clinical Surgery and General Surgical Unit, Western General Hospital, Edinburgh. Registrar, South-East Scotland Regional Blood Transfusion Centre, Royal Infirmary, Edinburgh.

\# Medical Student, Western General Hospital, Edinburgh.

Consultant Radiologist, Western General Hospital, Edinburgh.

Medical Physicist, Western General Hospital, Edinburgh.

Laboratory Assistant, South-East Scotland Regional Blood Transfusion Centre, Royal Infirmary, Edinburgh.

* Deputy Director, South-East Scotland Regional Blood Transfusion Centre, Royal Infirmary, Edinburgh.
}

1952 and 1961 at least one preventable death occurred every fortnight in the two major hospitals in Oxford. More recently, in a careful study of 263 right lungs, the same group found evidence of pulmonary emboli in $51.7 \%$ (Morrell and Dunnill, 1968).

Newer methods of diagnosing embolism include pulmonary angiography (Cooley, 1964; Littmann, 1965; Stein et al., 1967), isotope scanning (Wagner et al., 1964; Sabiston and Wolfe, 1967), and ultrasonics (Joyner et al., 1967). These advanced diagnostic techniques demand, in varying measure, considerable expertise, expense, and time. In angiography and isotope work there is some discomfort or risk to the patient, or both. None is ideal as a screening method for routine clinical use, and new and simpler diagnostic aids are urgently required.

During the proteolysis of fibrinogen and fibrin by the fibrinolytic enzyme plasmin several fragments are released which are unclottable and incapable of further digestion (Nussenzweig and Seligmann, 1960; Alkjaersig et al., 1962) Two of these fibrinogen/fibrin degradation products (F.D.P), the so-called $\mathrm{D}$ and $\mathrm{E}$ fragments, have an antigenic determinant which is related to the parent fibrinogen. This property has made it possible to adapt the tanned red cell haemagglutination inhibition immunoassay of Boyden (1951) to estimate serum F.D.P. quantitatively (Murakami, 1965; Merskey et al., 1966) and provide some information on the level of actual in-vivo fibrin deposition and lysis in those clinical states not associated with fibrinogenolysis. This technique is so sensitive that abnormally high values of serum F.D.P. can be detected before there is clear collateral evidence of a depletion of platelets, fibrinogen, and other coagulation factors. Thus immunoassay may be used to show occult intravascular coagulation and fibrinolysis, thereby offering a new approach to the diagnosis of suspected and occult venous thrombosis or pulmonary embolism, or both.

Earlier investigations in this laboratory ascertained the normal range of serum F.D.P. in adults (Das et al., 1967) and in infants and children (Uttley et al., 1969), and further pilot studies in patients after acute myocardial infarction and following surgical operations suggested that the measurement of these polypeptides may be useful in the diagnosis of acute 